\title{
Effects of Saharan Dust Advection on Atmospheric Aerosol Properties in the West-Mediterranean Area
}

\author{
G. Pavese, ${ }^{1}$ M. Calvello, ${ }^{1}$ F. Esposito, ${ }^{2}$ L. Leone, ${ }^{3}$ and R. Restieri ${ }^{3}$ \\ ${ }^{1}$ Institute of Methodologies for Environmental Analysis, National Council of Research, Contrada S. Loja, 85050 Tito Scalo, Italy \\ ${ }^{2}$ Environmental Engineering and Physics Department, Basilicata University, Contrada Macchia Romana, 85100 Potenza, Italy \\ ${ }^{3}$ Basilicata Asbestos Regional Center, Basilicata Regional Agency for the Environment, Via della Fisica, 18 C/D, 85100 Potenza, Italy
}

Correspondence should be addressed to G. Pavese, pavese@imaa.cnr.it

Received 22 November 2011; Revised 1 February 2012; Accepted 6 March 2012

Academic Editor: Pawan Gupta

Copyright ( $) 2012$ G. Pavese et al. This is an open access article distributed under the Creative Commons Attribution License, which permits unrestricted use, distribution, and reproduction in any medium, provided the original work is properly cited.

\begin{abstract}
Eight measurement campaigns for the characterization of atmospheric aerosol properties were conducted from 2001 until 2008 at five sites located in the Western Mediterranean basin. Radiometric measurements were used to obtain Aerosol Optical Depth, Ångström parameters, and aerosol size distributions, allowing differentiation of background conditions from anthropogenic, marine, or Saharan dust aerosol advection. The analysis was focused on the study of optical and physical properties variation of atmospheric aerosols under Saharan outbreaks. Dust-affected data were analysed all together, independently from the measurements site, thus allowing the highlighting of similarities and differences among them. The scatter-plot Ångström exponent versus AOD at $780 \mathrm{~nm}$ shows a correlation among all dust data, while an overlapping region with no-dust data reveals the simultaneous presence of mineral, anthropogenic, and marine particles. Daily averaged volume size distributions can be unimodal or bimodal functions and one three-modal distribution, with a coarse mode generally prevailing. Finally, considering the ratio of small/large particles $n_{s} / n_{l}$ and plotting the corresponding histogram for all dust data, a sharp frequency distribution is obtained with $89 \%$ of data in the range $5-65$, while $89 \%$ of no-dust data extend from 5 to 135 , in spite of different sources, pathways, and arrival sites.
\end{abstract}

\section{Introduction}

Atmospheric aerosols are one of the main sources of uncertainty in estimating Earth's radiation budget. This is due not only to the variability (in amount and composition) of locally produced particles but also to the nonnegligible transport phenomena, as highlighted in many recent studies such as Formenti et al. [1], Pace et al. [2], Meloni et al. [3], Kalivitis et al. [4], and Santese et al. [5].

The Western-Central Mediterranean basin, as well as its Eastern part, represents an area of crossing air masses originating in widely varying regions such as North-East and North-Central Europe, Atlantic Ocean, South-West Europe, and North Africa. In past years, some studies describing aerosol properties over this region (AladosArboledas et al. [6], Esposito et al. [7], Lyamani et al. [8]) have been published. In general, atmospheric particles can cause positive or negative feedback in the energy budget, depending on their chemical composition but, reducing solar radiation penetration toward the Earth's surface, they can also lead to a reduction in the evaporation of the Mediterranean sea. As a consequence, as described by Lelieveld et al. [9], a strong precipitation depletion can be observed, implying extreme consequences for such a highly populated area. On this subject, it must be reminded that even IPCC in 2007 (http://www.ipcc.ch/pdf/assessment-report/ar4/syr/ar4_syr .pdf) noticed that in the period 1900-2005 precipitation declined over the Sahel and the Mediterranean, and, since 1970, drought has been covering an even wider area.

Among the species of atmospheric particles, mineral dust represents one of the main component, whose optical and physical properties have to be investigated not only for its influence on Earth radiation budget but also for its relevant effect on air quality. In fact, its contribution to PM10 level limit exceedances cannot be disregarded, due to 
the even more frequent penetrations in European countries of dust aerosol coming from North Africa. For this reason, there is a strong need to properly estimate its contribution to the aerosol loading, as a natural contribution for air quality evaluation by European Union Member States, as stated in the "Guidance for State Members on PM10 measurements and the inter-comparison with the reference method" (http://ec.europa.eu/environment/air/pdf/finalwgreporten .pdf).

Moreover, dust effects on human health have to be taken into account because, in large cities, Aeolian dust particles can interact with anthropogenic aerosol, amplifying the effects of anthropic pollution. Perez et al. [10] investigated the effect of exposure to PM10 and PM2.5 on daily mortality in Barcelona, also in relation to particles composition: a difference between dusty and no-dusty conditions was found.

In past years, different instruments (radiometers, lidar, gravimetric particles samplers) and measurement configurations (ground-based, aircraft, and satellite) have been used to collect datasets describing mineral particles' physical and optical properties. According to their scope, measurements can furnish long-term data such as in AERONET (global Aerosol Robotic Network) (described by Kubilay et al. [11], Kalivitis et al. [4], Gobbi et al. [12], Santese et al. [5], and Kim et al. [13]) or short-term data for dedicated campaigns (Smirnov et al. [14], Lyamani [15], and Pavese et al. [16]). Although there have been progresses deriving from important campaigns (NAMMA, SAMUM, etc.), realised in dust-source regions for the characterization of dust properties, there is still a concern related to the variation of mineral aerosol properties during their transport. Formenti et al. in 2011 [17] urge, for future work, to focus scientific interest toward the variation of mineral dust properties when it moves far from the source site.

This paper aims to improve the knowledge on mixing effects of transported dust and atmospheric aerosols, thus partially satisfying this request. In this context, a study based on the analysis of eight radiometric datasets obtained in five different sites located in the Western Mediterranean area (Minimum Latitude $37.9^{\circ}$, Maximum Latitude $40.60^{\circ}$, Minimum Longitude $-3.61^{\circ} \mathrm{E}$, Maximum Longitude $15.72^{\circ} \mathrm{E}$ ) is discussed. Three of them can be considered as definitely rural, one is very weakly affected by anthropogenic activities, while the other one is an urban site.

Two main objectives have been pursued. First, the variations of aerosol optical and physical properties under the intrusion of mineral particles, as derived by high spectral resolution measurements of visible solar irradiance, are described.

The second objective is to group all data classified as dust affected in a sole global dataset and to look for similarities and/or discrepancies among them. In other words, we have considered and analysed the possibility that, in spite of the different characteristics of the measurement sites and their background aerosols, data representative of transported mineral particles properties show some common optical or physical behaviour or are each other correlated, thus giving further support to the comprehension of the transport phenomena effect on dust particles.

\section{The Experiments}

Ground-based sun photometry is recognised as a powerful technique to investigate optical and microphysical aerosol properties. In fact, spectral Aerosol Optical Depth (AOD) and Aerosol Size Distributions are two of the key parameters describing atmospheric particles and are useful to follow the evolution of aerosol characteristics, independently of their prevailing component as can be found in Toledano et al. [18] and Ilyinskaya et al. [19].

2.1. Experimental Set-Up. The eight campaigns for direct visible solar irradiance measurements involved in this study span, not continuously, a wide time period (2001-2008). They have been realized by using three different highresolution spectrometers: firstly, a Monolight radiometer equipped with a diffraction grating and a silicon detector, working on the spectral range $400 \mathrm{~nm}-800 \mathrm{~nm}$ and $3 \mathrm{~nm}$ of resolution. The other two instruments are an Avantes and an Ocean Optics radiometer whose core is a CCD (ChargeCoupled Device) detector, both covering the wavelengths range $400 \mathrm{~nm}-800 \mathrm{~nm}$ with resolution $1.5 \mathrm{~nm}$. All three spectrometers are coupled, via wave-guide, with a light focusing system whose FOV is $1^{\circ}$. This solution ensures that diffuse solar radiation does not affect direct solar spectra. Direct solar irradiance measurements are usually collected every 15 minutes, in cloudless conditions, from sunset to sunrise. The equipment is manually operated and the measurements can be considered unaffected by visible clouds passage. The presence of subvisible and cirrus clouds are taken into account in the data preprocessing phase, as explained in the following.

2.2. Data Processing. For each measurement campaign the radiometers have been previously calibrated in the proper site and atmospheric conditions according to the Langley procedure. The Aerosol Optical Depth is estimated over the spectral range $400 \mathrm{~nm}-800 \mathrm{~nm}$ from Total Optical Depth, subtracting both Rayleigh and Chappuis ozone contributions and avoiding the strong molecular bands (oxygen and water vapour). The ozone optical depth correction in the weak Chappuis band is calculated by using daily values of the ozone content, as derived from the TOMS website (http://toms.gsfc.nasa.gov/eptoms/ep.html). The AODassociated error has been statistically calculated, as described in Esposito et al. in 2003 [20]. In particular, considering $\mathrm{AOD}$ at $500 \mathrm{~nm}$ values, an error ranging from $1.5 \%$ to $10 \%$ has been estimated for Monolight radiometer, while for both Avantes and Ocean Optics the error variation range is 1\%$10 \%$. It must be pointed out that for all instruments, data with an error higher than $10 \%$ have not been included in the analysed dataset. Estimations of the Ångström parameters $\alpha$ and $\beta$ are obtained by a best-fit procedure applied to all spectral AOD values. Considering the entire dataset, the percentage error on $\alpha$ values oscillates around 2\% with very few data with percentage errors as high as $10 \%$. Although the instrument is manually operated, even data affected by external noises such as thin invisible cirrus can be recorded. 
For this reason measurements analysed in the present work have been selected from a wider dataset. In fact, AOD spectra whose values exceeded their corresponding best-fit values more than $20 \%$ have been excluded. In this way, data out of two standard deviations have not been analysed. The whole procedure is described in detail in Esposito et al. [7].

The list of parameters used to describe aerosol optical properties variation is completed by the Aerosol Size Distribution, expressed as $d V(r) / d(\ln r)\left(\mathrm{cm}^{3} / \mathrm{cm}^{2}\right)$. The inversion procedure applied to the AOD data for size distribution retrieval is a Twomey-modified nonparametric technique with a second derivative regularization, tested and discussed in Amato et al. [21]. Shortly, two points about it have to be remembered: first, the retrieval process is an iterative one and, applied to the measured AOD in the wavelengths range $400 \mathrm{~nm}-800 \mathrm{~nm}$, gives back size distributions on the radii range $0.1 \mu \mathrm{m}-3 \mu \mathrm{m}$, where the technique has been found much more reliable and, at the same time, where Saharan dust particles can be easily detected. The second point is that a Junge function is used as a first guess of the procedure, with fixed refractive index $1.45+0.0 \mathrm{i}$. This last choice does not invalidate our results because, as verified in the past, according to Gonzàlez and Ogren, [22], to Alados-Arboledas et al. [6], and to Ilyinskaya et al, [19], even with varying real and imaginary parts of the refractive index, the shape of the retrieved functions is retained.

The uncertainties associated with the retrieved size distributions, in the size range $0.1-1.4 \mu \mathrm{m}$, have been estimated, on average, to be $\leq 5 \%$ for both low and high particles content. In the large particle range $(1.6-3 \mu \mathrm{m})$, in the case of low aerosol loading, this error increases until $100 \%$, while it remains below $30 \%$ for high particles loading.

2.3. Measurement Sites. The five ground-based measurements sites are situated, respectively, three in South Italy and two in South Spain. In particular in Italy there is Tito Scalo $\left(40.60^{\circ} \mathrm{N}, 15.72^{\circ} \mathrm{E}, 750 \mathrm{~m}\right.$ a.s.l. $)$ which is a very small industrial zone located in a wider rural area, about $750 \mathrm{~m}$ from a main road. The distances from the seas are $70 \mathrm{~km}$ from the Tirrenian Sea, $90 \mathrm{~km}$ from the Adriatic Sea, and $95 \mathrm{~km}$ from the Ionian Sea. Keeping in mind these considerations, locally produced aerosol can be rural, that is, uplifted soil particles, vapours emitted by a close brick-kiln, and emissions from diesel vehicles. Marineadvected particles, as confirmed by the HYSPLIT backtrajectories analysis, contribute quite often to the atmosphere composition, as well as anthropogenic particles from NorthEastern Europe, while increasing Saharan dust outbreaks can be detected during the year.

The second Italian site, called Piano Ruggio ( $1550 \mathrm{~m}$ a.s.l., $39.91^{\circ} \mathrm{N}, 16.12^{\circ} \mathrm{E}$ ), is a flat area surrounded by higher peaks, situated on the Pollino massif, not so far from the seas ( $28 \mathrm{~km}$ from the Tirrenian Sea and $40 \mathrm{~km}$ from the Ionian Sea). It is a rural site with vegetation mainly constituted by grass and woods. During the campaign, which took place at the beginning of the 2003 heat wave, the air masses backtrajectories have been travelling from North Europe, close to the Tirrenian Sea and from North Africa.
The third site is Toppo di Castelgrande $\left(40.82^{\circ} \mathrm{N}\right.$, $15.45^{\circ} \mathrm{E}, 1258 \mathrm{~m}$ a.s.l.), which is the highest peak in a wide rural area and for this reason it hosts an astronomical observatory. It is about $55 \mathrm{~km}$ from the Tirrenian Sea and $85 \mathrm{~km}$ from the Adriatic Sea. Its vegetation is characterised by brushwood and few shrubs. In this case, local particles production can be considered not very present, except for soil particles uplifted by the wind. In this case the air particles have been moving from North-East, Central, and NorthWest Europe.

The two remaining sites are both situated in South Spain: one is Tabernas $\left(37.09^{\circ} \mathrm{N},-2.23^{\circ} \mathrm{E}, 486 \mathrm{~m}\right.$ a.s.l.), the only European desert area, whose characteristics are due to the presence of Sierra de Los Filabres and Sierra de Alhamilla which protect Tabernas from the Mediterranean Sea influence and humidity. The measurements campaign has been realized at the Plataforma Solar station and air mass paths have been found to travel from Eastern Europe or the Atlantic Ocean or the Mediterranean Sea and North Africa.

The last measurement site is Granada $\left(37.16^{\circ} \mathrm{N},-3.60^{\circ} \mathrm{E}\right.$, $680 \mathrm{~m}$ a.s.l.), a well-known nonindustrialized city, the capital of the Andalucia region in South Eastern Spain. Granada is a medium-sized city (about 300,000 inhabitants), protected by the Sierra Nevada mountains, located in a natural basin and $50 \mathrm{~km}$ from the western Mediterranean basin and $200 \mathrm{~km}$ from Africa. The measurement campaign took place on the roof of the Centro Andaluz de Medio Ambiente (CEAMA), at about $15 \mathrm{~m}$ from the ground level. Anthropogenic particles from diesel vehicle traffic characterize the local atmosphere, but occurrences of Saharan particles intrusion from North Africa have been encountered along the whole campaign.

The durations of the measurement campaigns were very different: in fact, data registered in Tito Scalo represent the largest dataset since the instruments here are usually located and it is possible to monitor aerosol properties variation on a wider time scale. Nevertheless, all the sites, except Toppo di Castelgrande, have been affected by mineral particles advection and this allows the study of the mixing effect of dust with local produced and/or other advected aerosols.

In Table 1 there is a list of each campaigns' descriptive data, with site name, corresponding geographical coordinates and elevation, instruments, campaign duration, mean, at values, and their standard deviations for AOD at 780 and alpha parameter. The complete dataset consists of about 1500 measures, distributed over 72 days of measurements.

\section{Data Analysis}

3.1. AOD and Angström Parameters. The biggest part of the data, independently of the site, has been mainly obtained during the summer period (June-August), with few measurements collected in the spring (April-May) and fall (September-October) seasons. An obvious reason for this is that those months are highly cloudless and allow a more continuous monitoring of the atmosphere; the other is that dust events are much more frequent during summer. In fact, as explained by Alpert et al. [23], in July and August both the East Mediterranean area and North-Central Africa are 
TABLE 1: List of the measurement campaigns with site, geographic coordinates and elevation, instrument used, duration, number of measurements, mean AOD at 780 and standard deviation, mean alpha, and standard deviation.

\begin{tabular}{|c|c|c|c|c|c|c|}
\hline Site name & $\begin{array}{c}\text { Geographic } \\
\text { coordinates and } \\
\text { elevation }\end{array}$ & Instrument & $\begin{array}{l}\text { Campaign } \\
\text { duration }\end{array}$ & $\begin{array}{c}\text { Total measures } \\
\text { number }\end{array}$ & $\begin{array}{c}\left\langle\mathrm{AOD}_{780}\right\rangle \pm \text { Stand } \\
\text { Dev. }\end{array}$ & $\begin{array}{c}\langle\text { alpha }\rangle \pm \text { Stand } \\
\text { Dev. }\end{array}$ \\
\hline Tito Scalo 2001 & $\begin{array}{c}40.60^{\circ} \mathrm{N} 15.72^{\circ} \mathrm{E} \\
750 \mathrm{~m} \text { a.s.l. }\end{array}$ & Monolight & June-October & 342 & $0.15 \pm 0.06$ & $1.42 \pm 0.37$ \\
\hline Pollino 2003 & $\begin{array}{c}39.91^{\circ} \mathrm{N} 16.12^{\circ} \mathrm{E} \\
1550 \mathrm{~m} \text { a.s.l. }\end{array}$ & Avantes & June, $24-27$ & 145 & $0.18 \pm 0.11$ & $1.2 \pm 1.0$ \\
\hline Tabernas 2003 & $\begin{array}{c}37.09^{\circ} \mathrm{N}-2.36^{\circ} \mathrm{E} \\
486 \mathrm{~m} \text { a.s.l. }\end{array}$ & Avantes & Sept, $16-25$ & 252 & $0.09 \pm 0.06$ & $1.44 \pm 0.57$ \\
\hline Castelgrande 2004 & $\begin{array}{c}40.82^{\circ} \mathrm{N} 15.45^{\circ} \mathrm{E} \\
1258 \mathrm{~m} \text { a.s.l. }\end{array}$ & Avantes & June, 8-10 & 84 & $0.09 \pm 0.05$ & $1.46 \pm 0.45$ \\
\hline Tito Scalo 2004 & $\begin{array}{c}40.60^{\circ} \mathrm{N} 15.72^{\circ} \mathrm{E} \\
750 \mathrm{~m} \text { a.s.l. }\end{array}$ & Avantes & July, 6-28 & 182 & $0.18 \pm 0.06$ & $1.47 \pm 0.46$ \\
\hline Granada 2006 & $\begin{array}{c}37.16^{\circ} \mathrm{N}-3.60^{\circ} \mathrm{E} \\
680 \mathrm{~m} \text { a.s.l. }\end{array}$ & Avantes & July, 13-19 & 87 & $0.25 \pm 0.06$ & $0.61 \pm 0.27$ \\
\hline Tito Scalo 2007 & $\begin{array}{c}40.60^{\circ} \mathrm{N} 15.72^{\circ} \mathrm{E} \\
750 \mathrm{~m} \text { a.s.l. }\end{array}$ & $\begin{array}{c}\text { Avantes/ Ocean } \\
\text { Optics }\end{array}$ & April, October & 96 & $0.21 \pm 0.09$ & $1.29 \pm 0.21$ \\
\hline Tito Scalo 2008 & $\begin{array}{c}40.60^{\circ} \mathrm{N} 15.72^{\circ} \mathrm{E} \\
750 \mathrm{~m} \text { a.s.l. }\end{array}$ & Ocean Optics & May-September & 300 & $0.17 \pm 0.13$ & $1.35 \pm 0.68$ \\
\hline
\end{tabular}

under the subtropical high, allowing the Sharav cyclones generated at the lee of the Atlas mountains only one way to leave, which is across the West Mediterranean subbasin. This marked seasonal behaviour allows dust mineral particles to be carried and transported over the aforementioned area.

The arrival of mineral particles is usually related to AOD values increasing and alpha exponent values decreasing: this occurrence has been observed by Lyamani et al. [8], Fotiadi et al. [24], and Pace et al. [2].

In the present study, background conditions have been found to be different site by site but a threshold value of 0.15 for AOD at $780 \mathrm{~nm}$ together with alpha values lower than 1.4 could be considered as first indicators of a presence of transported mineral aerosols. To support dust intrusion hypothesis, air masses backtrajectories have been generated by Hybrid Single-Particle Lagrangian-Integrated Trajectory Model. (HYSPLIT). This tool (http://ready.arl.noaa.gov/HYSPLIT.php) is frequently used by scientists to support their studies in aerosol source identification.

To this end, 5-day back-trajectories have been generated from $500 \mathrm{~m}$ to $4500 \mathrm{~m}$ a.g.l. (above ground level), each $500 \mathrm{~m}$ : this choice has been suggested by di Sarra et al. in 2001 [25] which found African dust layers mainly located at $4 \mathrm{~km}$ a.s.l. and, sometimes, up to $7-8 \mathrm{~km}$ a.s.l. When available, additional tools for dusty days identification have been Navy Aerosol Analysis and Prediction System (NAAPS, http://www.nrlmry.navy.mil/aerosol/) maps, Terra, and Aqua images (http://modis.gsfc.nasa.gov/). The complexity of the atmospheric circulation often leads to situations where particles of different origin mix together: in these cases, retrieved optical and physical properties of the aerosols are attributed to one kind of particles instead of another, depending on how many and how high above the ground are the back trajectories, and how long they skim over a certain region.

Given all this, AOD values at $780 \mathrm{~nm}$ and their variations have been chosen as an indicator of the presence of large particles: Figure 1 (a) reports two histograms of $\mathrm{AOD}_{780}$, one for all no-dust measurements and the other one for dustaffected (pure and mixed dust) data only. The first histogram covers values from 0.03 to 0.39 and exhibits a main peak around 0.11 and a smaller one centred around 0.21 , with overall average value 0.12 and standard deviation 0.07 . The second histogram is a very broad distribution covering a value range from 0.15 to 0.57 with maximum value at 0.25 : in this case the AOD average value is 0.26 with standard deviation equal to 0.09 . This broadness can be explained by the different strength of Saharan dust outbreaks. Since the secondary peak of the first histogram overlaps AOD values of dust distribution, it could be expected that even those data correspond to dust aerosols but air masses pathways reveal trajectories with a high load of marine particles.

In order to have confirmation of this hypothesis, the histogram of total $\mathrm{AOD}_{780}$ values (except dust/mixed dust points) and the one corresponding to sea-salt prevailing particles are reported in Figure 1(b): it is evident how marine particles strongly contribute to the second peak of global measures. It must be pointed out that sea-spray aerosol data correspond to measurements obtained in Tito Scalo only during the 2001, 2004, 2007, and 2008 campaigns. The broadness (AOD values ranging from 0.09 to 0.39 , average value 0.21 , standard deviation 0.07 ) of marine particles distribution is due to different mixing contributions with other kinds of particles, which can be, in turn, anthropogenic aerosol transported from industrial areas of North-Central Europe or rural aerosol locally produced by wind soil erosion. 


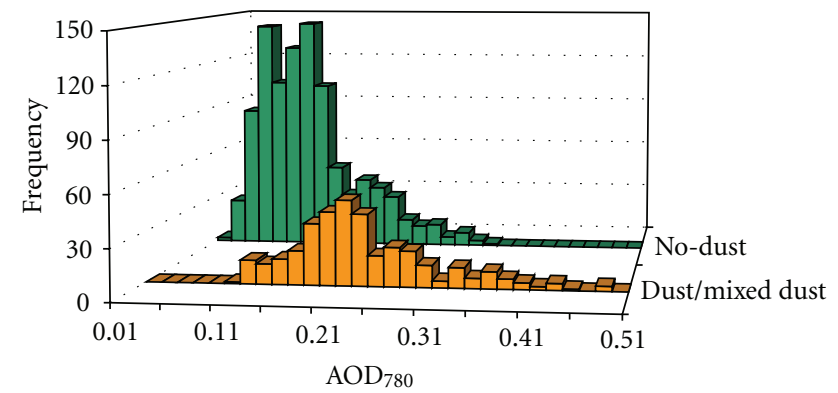

(a)

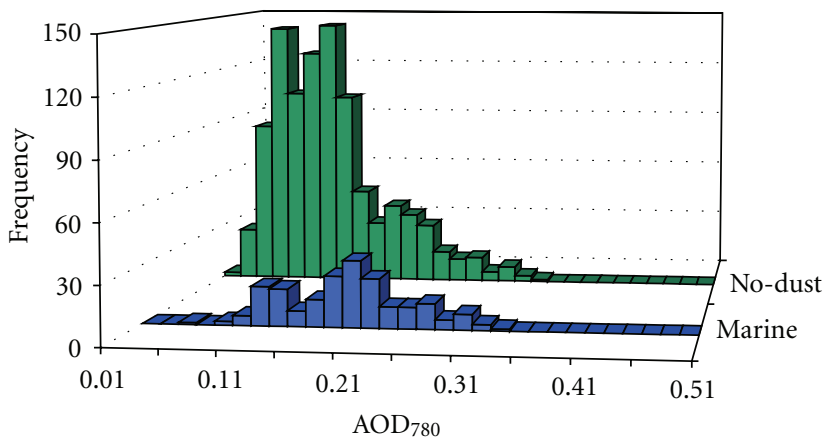

(b)

FIGURE 1: Histograms of AOD at $780 \mathrm{~nm}$ (a) comparing dust/mixed dust and no-dust data and (b) comparing no-dust and marine data.

In Figures 2(a) and 2(b) alpha values corresponding to the $\mathrm{AOD}_{780}$ of Figures 1(a) and 1(b) are reported: no-dust distribution extends from 0.60 to 4.55 with mean value 1.57 and standard deviation 0.56 , whereas dust/mixed dust distribution runs from 0.20 to 1.40 (mean $=0.70$, standard deviation $=0.33$ ).

It must be pointed out that alpha values higher than 4 have also been considered, because the Ångström power law is a semiempirical one and departures from that are reported in the literature as in Kaskaoutis et al. [26].

In the alpha values range $0.73-1.40$ there is an overlap of dust and no-dust data. This can be explained as follows: low alpha values in no-dust distribution can be attributed to sea-salt aerosol, as partially supported by marine distribution in Figure 2(b), or to some local wind effect of particle uplift in rural sites, such as in Tito Scalo or Tabernas. On the other hand, higher alpha values in the dust plot are due to conditions where a heavy concentration of mineral particles (high $\mathrm{AOD}_{780}$ ) is mixed with a considerable small particle concentration (growing alpha values).

The overlapping region between dust and no-dust data is much more evident if one looks at the scatter-plot alpha parameter versus $\mathrm{AOD}_{780}$ in Figure 3.

Here triangles represent dust-affected data and rhombus stand for all the other kinds of particles, while the ellipse contains the overlapping area whose variation ranges are, respectively, $0.73 \leq \alpha \leq 1.40$ and $0.10 \leq \mathrm{AOD}_{780} \leq 0.24$ : it can be easily seen that dust points merge into no-dust points, showing a continuity of behaviour. If we consider no-dust data only, for low AOD values (less than 0.1 ) a fast variation in alpha is found with values as high as 4.8 , meaning that in this region a variety of particulate composition is contained with prevailing small particles, both anthropogenic or fire products.

This result is in agreement, for example, with Kalivitis et al. [4], even though their data come from a single AERONET site which is FORTH-CRETE, while our data have been collected in several sites, each of them characterised by different background conditions. Moreover, in this plot two datasets contained in no-dust data have to be noticed: one is in the area $\mathrm{AOD}_{780}>0.15$ and $1<$ alpha $<2$; the other is in $\mathrm{AOD}_{780}<0.15$ and alpha $<1.2$. In the first case the points follow a kind of flat behaviour and it has been verified that these data correspond to measurements all obtained in Tito Scalo during late the springtime/summer period, but in different years. This probably means that we are dealing with data recorded in similar conditions of air masses circulation. A check with HYSPLIT-generated backtrajectories revealed both westward and eastward air flows, giving two main contributions to the atmospheric particulate which are marine (from both Adriatic and Tyrrhenian seas) and anthropogenic (from Central-Eastern Europe) aerosols, with air masses even travelling grazing the ground. This also explains the relatively high AOD values. In the second case, data under analysis come from the Tito and Tabernas campaigns whose masses' back-trajectories were essentially affected by sea-salt aerosols (West-Mediterranean basin, Adriatic Sea), by some locally produced dust and some light anthropogenic influence from the Po Valley and NorthCentral Europe, since in this case the air masses were moving not very close to the ground.

3.2. Aerosol Size Distributions. In literature, alpha values less than 1 generally describe conditions of dust aerosol predominance. In fact, Fotiadi et al. [24] identified dust for $\alpha$ $\leq 0.5$, Kalivitis et al. [4] for $\alpha \leq 0.7$, Dubovik et al. [27] for $\alpha$ $\leq 0.9$, while Kim et al. [13], in a recent study, consider pure dust aerosol characterised by $\alpha \leq 0.2$. In particular, Fotiadi et al. [24] analysed aerosol properties from the AERONET station in Crete computing the alpha parameter from AOD at 440 and $880 \mathrm{~nm}$. These wavelengths correspond to the spectral range used in the present study $(400-800 \mathrm{~nm})$ where alpha values $\leq 0.5$ will describe measurements with intense dust intrusions, while $\alpha>0.5$ will characterize conditions with dust mixed with sea-salt and/or anthropogenic aerosols.

In Figures 4(a) and 4(b) daily averaged aerosol size distributions corresponding to, respectively, $\alpha \leq 0.5$ and $\alpha$ $>0.5$ are reported as $d V(r) / d \ln (r)\left(\mathrm{cm}^{3} / \mathrm{cm}^{2}\right)$.

Although the distributions in Figure 4(a) correspond to intense dust loading, they are differently shaped, probably depending on the mixing effect of mineral aerosols with other atmospheric particles. In fact, unimodal functions (Pollino, 2003) along with bimodal (Tito, 2001) and threemodal size (Tito, 2008) distributions have been retrieved. 


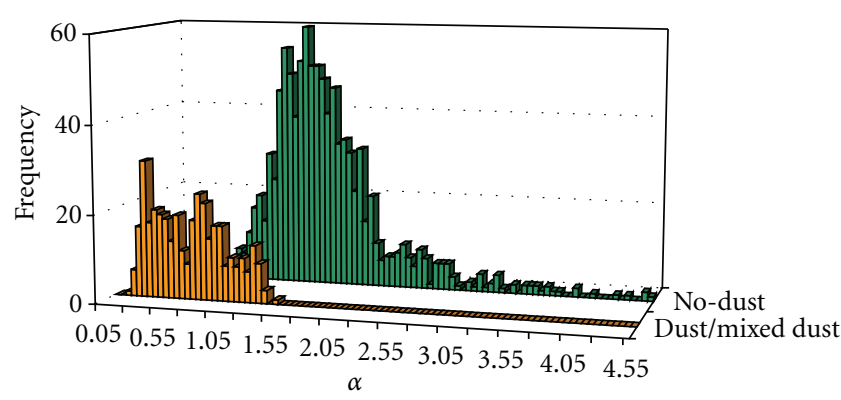

(a)

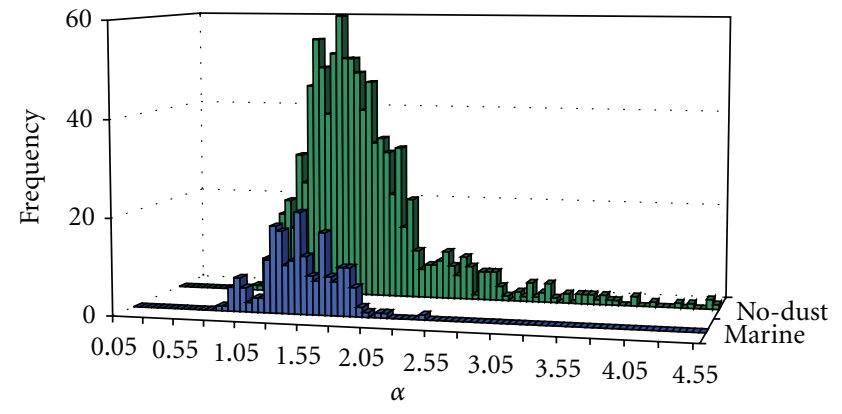

(b)

FIGURE 2: Histograms of alpha parameter (a) comparing dust/mixed dust and no-dust data and (b) comparing no-dust and marine data.

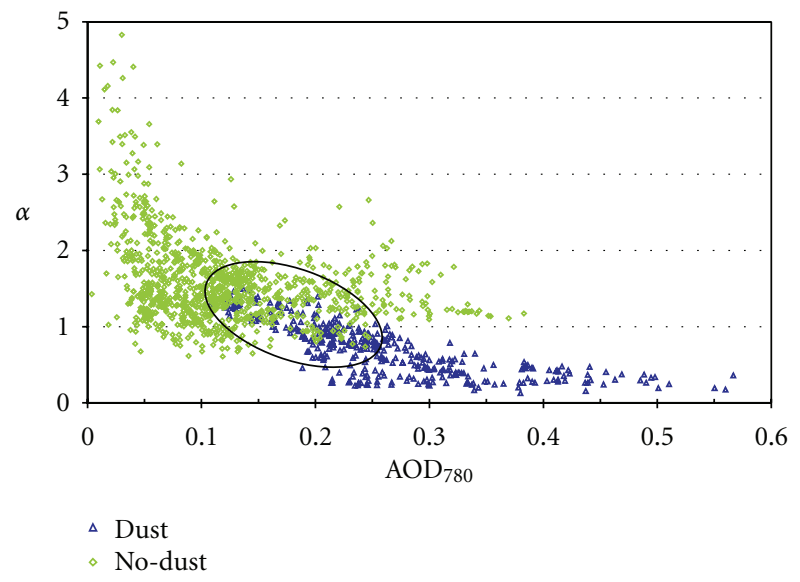

FIGURE 3: Scatter-plot alpha parameter versus $\mathrm{AOD}_{780}$ : blue triangles represent dust data, and green rhombus represent no-dust data. Black ellipse contains dust data overlapping no-dust data, corresponding to mixed aerosols.

Although it had a short duration (4 days), the Pollino 2003 campaign offered the possibility to analyse atmospheric conditions with very low aerosol burden (June, 25 th, $\left\langle\tau_{780}\right\rangle$ $=0.07 \pm 0.03,\langle\alpha\rangle=2.1 \pm 1.2)$ and others with strong Saharan dust intrusion (June, 26th, 4:23-8:32 a.m., $\left\langle\tau_{780}\right\rangle$ $=0.31 \pm 0.01,\langle\alpha\rangle=0.42 \pm 0.04$ and June, 27 th,$\left\langle\tau_{780}\right\rangle=$ $0.27 \pm 0.05,\langle\alpha\rangle=0.27 \pm 0.04)$. Due to the arrival of desert air-masses, a well-defined coarse mode would be expected. Instead, the averaged size distributions are still unimodal but centred toward coarse particles: as an example, on June 26 , an increasing particle volume in the size range $0.28 \mu \mathrm{m}-$ $2.80 \mu \mathrm{m}$, if compared with background conditions, can be observed. Considering that this site is located in a natural park at $1550 \mathrm{~m}$ a.g.l., the contribution of locally produced aerosol can be certainly excluded and, according to the backtrajectories, it can be assumed that different particles have been uplifted at different heights: mineral aerosol at higher levels and marine aerosol at lower levels.

The bimodal size distribution (October 4, Tito 2001) exhibits a second mode maximum at $0.94 \mu \mathrm{m}$, which is in agreement with the second mode obtained by Kubilay et al.
[11] (April 2000) in the rural town of Erdemli, South-Eastern coast of Turkey, under intense Saharan aerosol advection.

The Granada campaign has been characterised, even if with different intensity, by mineral particles intrusion for the largest part of its duration, as once again supported by HYSPLIT back-trajectories. The days of high mineral particle content (July, 15th, 17th, and 19th) are characterised by the following daily mean alpha values which are, in order, $0.39 \pm$ $0.07,0.29 \pm 0.09$, and $0.38 \pm 0.07$. Corresponding daily mean size distributions cannot be considered as clear bimodal functions: in particular, on July 17 an inflection point at $0.48 \mu \mathrm{m}$ can be identified with the coarse mode centred at high radius values $(>2 \mu \mathrm{m})$. The shape of these functions thus suggests a contribution at volume fine particles originating in urban vehicular traffic and in some smoke in the neighbourhood shown by NAAPS maps, particularly for July 17. The extended coarse mode found on July 17 and 19 shows a high contribution of large particles to the distributions: for these days, NAAPS maps highlight the Andalucia region as much more affected by dust mineral intrusion than others.

The three-modal distribution obtained in Tito on May, 28th 2008 can be considered unique among the wide family of functions retrieved so far: the first mode can be identified with the accumulation mode $(r \leq 0.1 \mu \mathrm{m})$, the second is located around $0.55 \mu \mathrm{m}$, and the third one is centred at $1.86 \mu \mathrm{m}$. For this day, as reported in Figure 5, the fiveday low-level backward trajectories (ending points $500 \mathrm{~m}$ and $1000 \mathrm{~m}$ ) have been observed travelling over the Balkan area and this can explain the fine particles loading. All the highest trajectories (ending points $1500 \mathrm{~m}-6500 \mathrm{~m}$ ), instead, have been crossing a very wide area of North Africa (from Mauritania to Mali and Algeria) and this accounts for large aerosol modes.

Only a specific analysis of the atmospheric aerosol composition, such as a chemical one, can help to unambiguously attribute the coarse modes to one kind of particles or another, but the longer period that air masses spent over desert areas, without an effective deposition process, can explain the broadness of the coarse modes, extended to a wider size range.

The functions corresponding to $\alpha>0.5$ and reported in Figure 4(b) are unimodal and bimodal, with modes poorly pronounced. Only during Tito 2001 do bimodal functions 
Tito 01
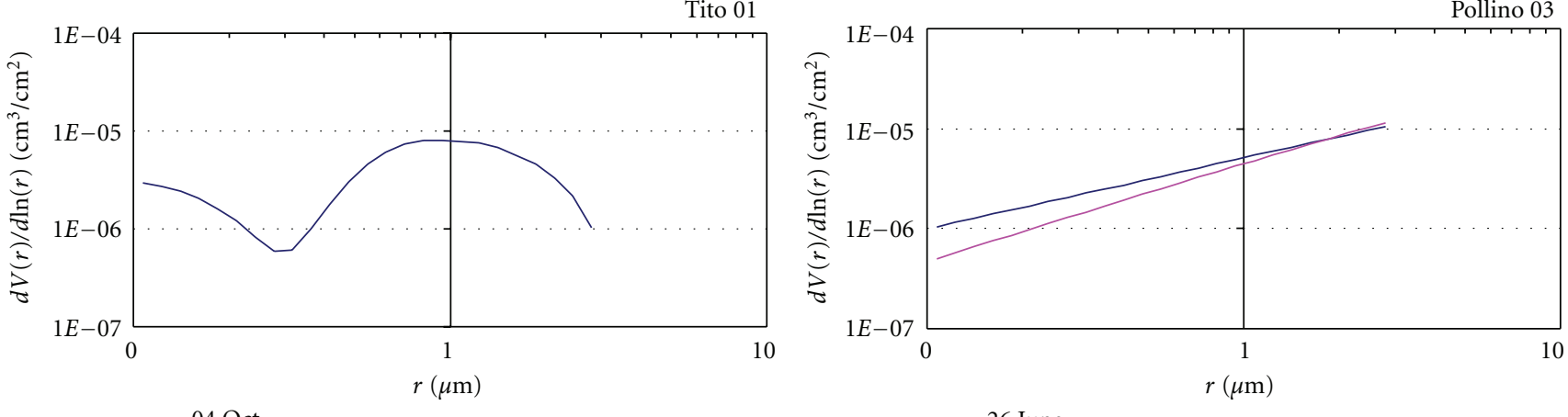

- 26 June

- 27 June
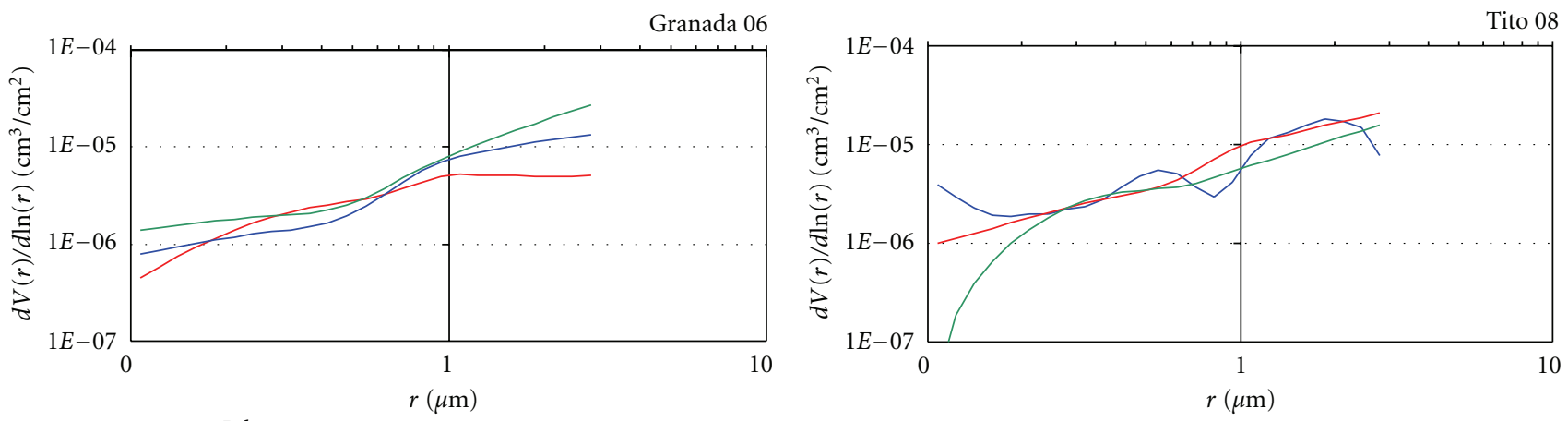

15 July
$-\quad 17$ July

28 May
$-\quad 08$ July

- 19 July

(a)

Tito 04

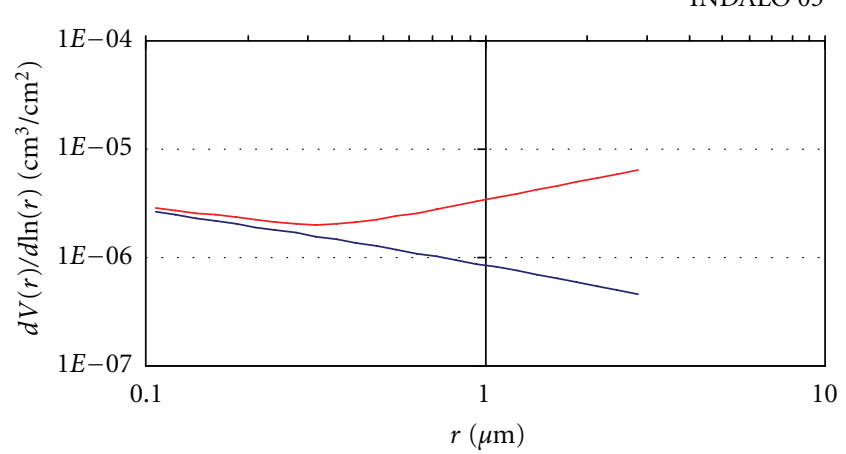

- 19 Sept

- 17 July

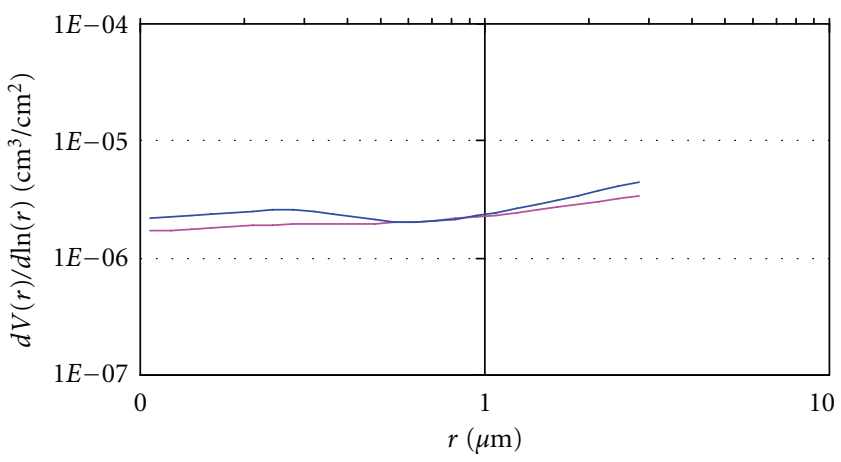

- $21 \mathrm{Sept}$

- 7 July

Tito 2001

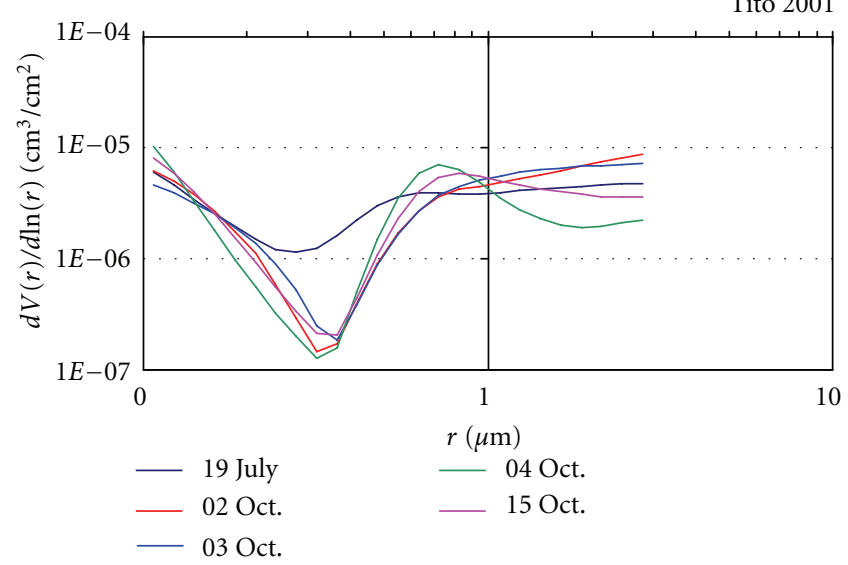

Pollino 03

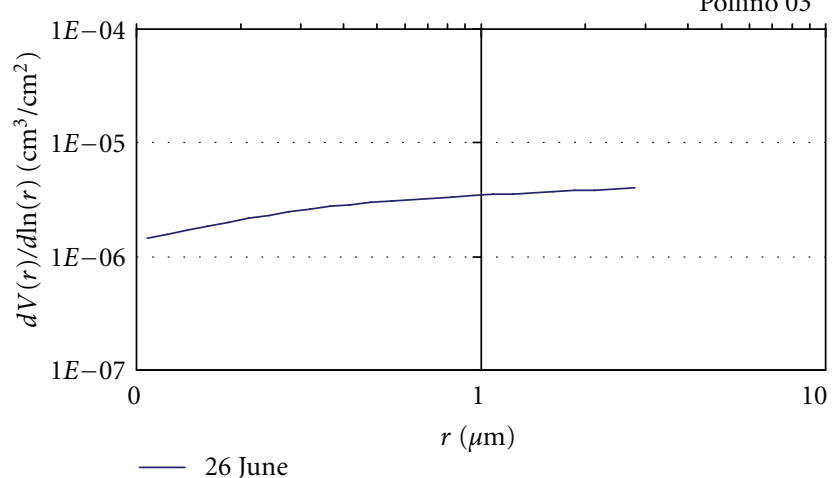

Figure 4: Continued. 
Granada 06

Tito 07
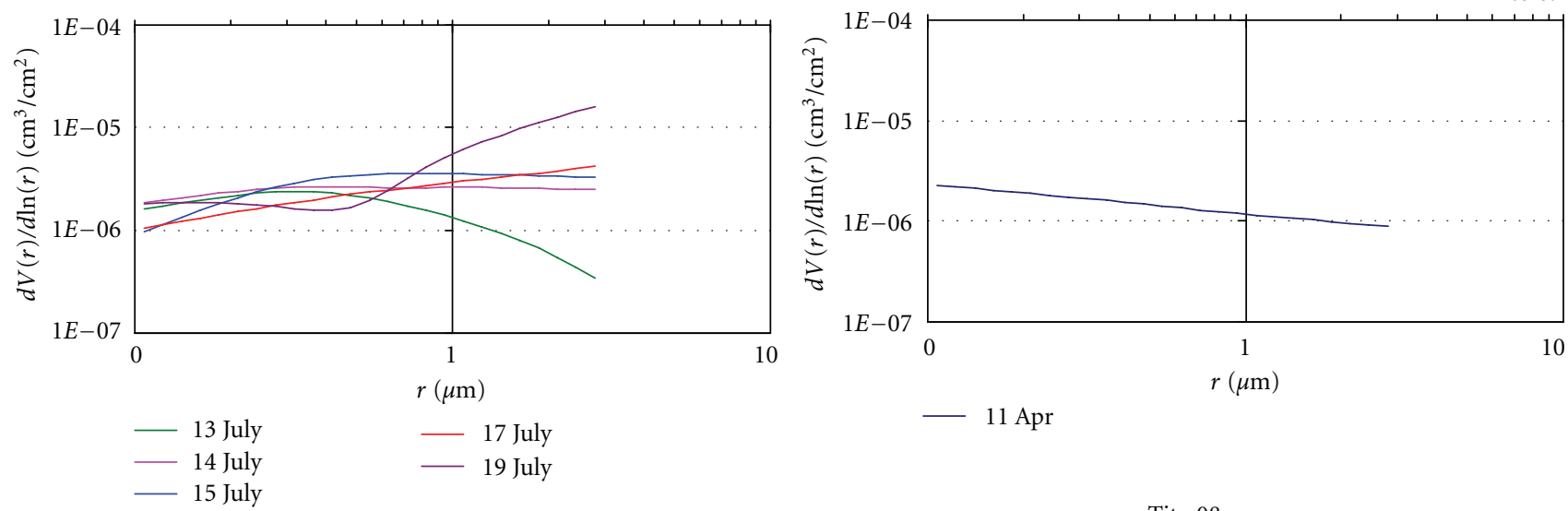

- 14 July

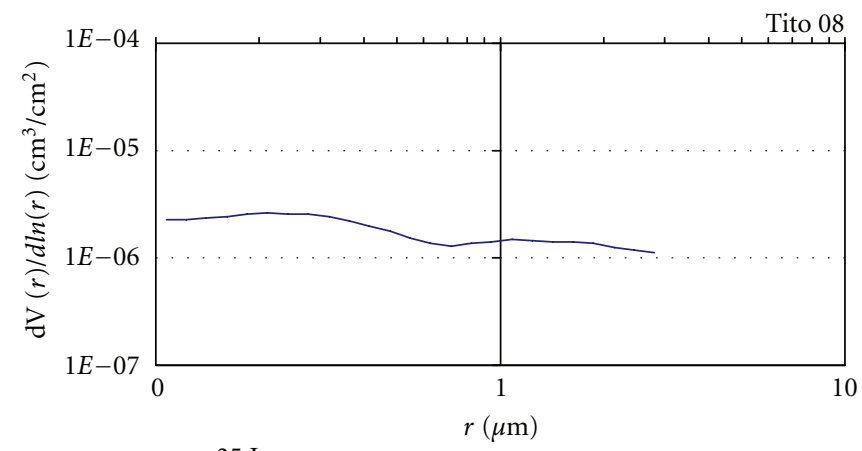

- 25 June

(b)

Figure 4: (a) Retrieved dust size distributions corresponding to $\alpha \leq 0.5$ and (b) dust size distributions corresponding to $\alpha>0.5$.

NOAA HYSPLIT model Backward trajectories ending at 10 UTC 28 May 08 GDAS meteorological data

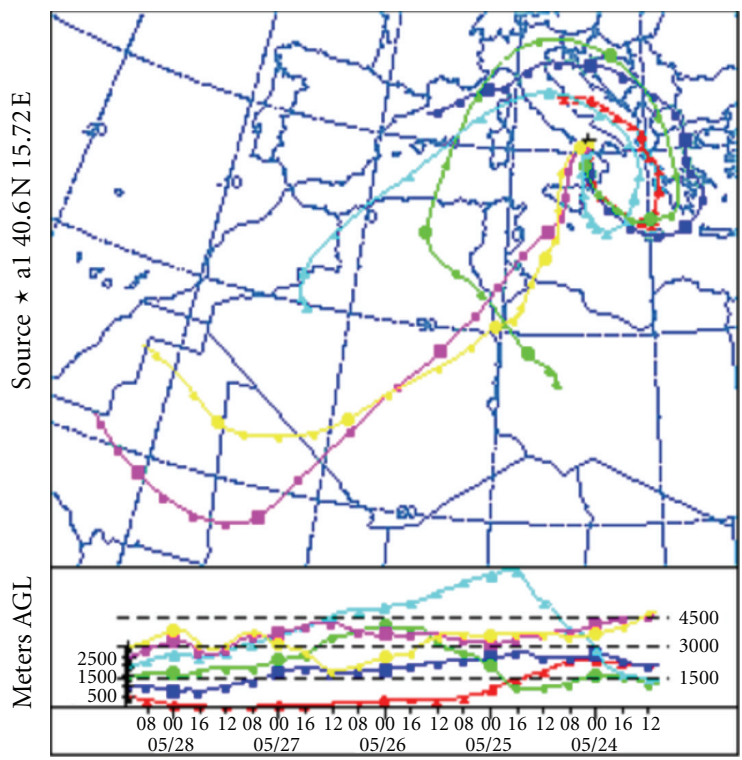

(a)
NOAA HYSPLIT model Backward trajectories ending at 10 UTC 28 May 08 GDAS meteorological data

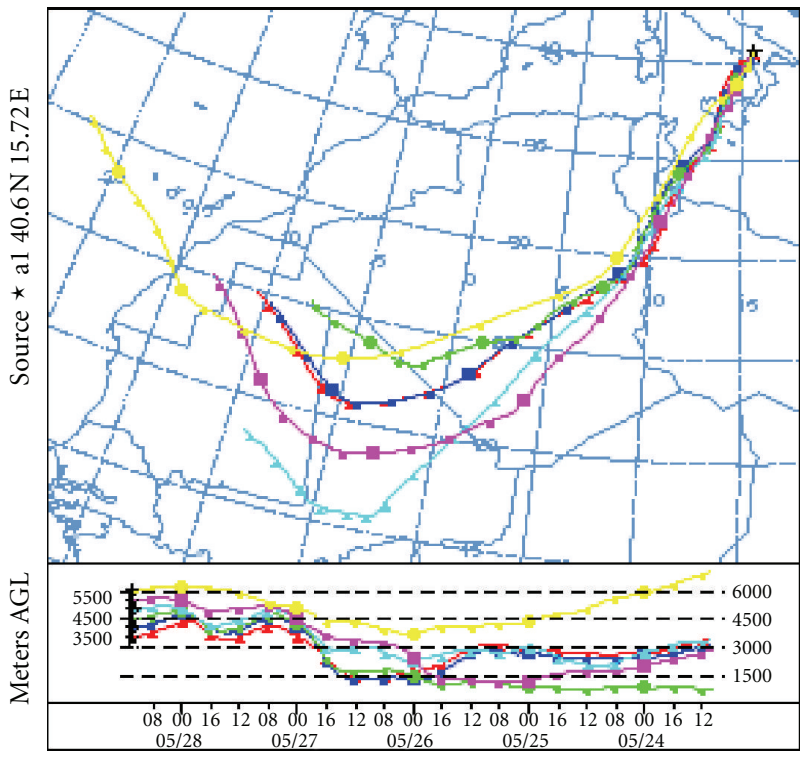

(b)

FIgure 5: Low-level and high-level back-trajectories for May 28, 2008. 
with maximum value oscillating between 0.63 and $0.82 \mu \mathrm{m}$ characterize October dusty days with a daily mean alpha parameter ranging between $0.81 \pm 0.15$ and $0.95 \pm 0.19$. On July 19 , the distribution is not clearly two peaks shaped, due to the contribution of particles in the size range 0.28 $0.55 \mu \mathrm{m}$ : in this case $\langle\alpha\rangle=0.77 \pm 0.13$.

During Tito 2004, July 7 and 8 were both characterised by Saharan dust loading in the higher particle paths (from $2000 \mathrm{~m}$ to $4500 \mathrm{~m}$ a.g.l.), but July 8 has, additionally, an urban loading in the lower trajectories (from $500 \mathrm{~m}$ to $1500 \mathrm{ma.g.l}$.) and intense fire concentration detected by NAAPS maps. This occurrence allowed the particle content in the size range $0.1 \mu \mathrm{m} \leq r \leq 0.42 \mu \mathrm{m}$ to be higher on July 8 than July 7 . In these cases the mean alpha values are, respectively, $0.92 \pm 0.24$ and $0.85 \pm 0.12$. Comparing the Junge distribution obtained on April 11 (Tito 2007) with those retrieved in Tito 2001, a higher contribution in the size range $0.18-0.55 \mu \mathrm{m}$ is observed. For this day backward trajectories suggest the presence of two concurrent advection phenomena which are dust and marine particles transport. In fact, on April 11 lower trajectories (ending points $500 \mathrm{~m}-$ $1500 \mathrm{~m}$ ) were moving very close to the Tyrrhenian sea surface $36-48 \mathrm{~h}$ before their arrival in the measurements site. Higher paths (3000 m-3500 m), instead, were travelling for two days very close to Libian and Algerian soils.

On September 19 (INDALO campaign), the retrieved function is still unimodal and, if compared with a distribution characteristic of Tabernas background conditions, shows higher values on the overall radii range and an increment of the volume particles in the size range $0.36 \mu \mathrm{m}-$ $1.23 \mu \mathrm{m}$. On September 21, it seems that two branches of two modes (fine and coarse) can be identified: in this case HYSPLIT back-trajectories highlight low-level paths strongly located and flattened over Algeria and Morocco, while marine particles could have been loaded $24-36 \mathrm{~h}$ before their arrival in the measurements site.

As said before, Granada measurements have been characterised by two main components: large mineral particles from North Africa and fine anthropogenic aerosols locally produced by vehicular traffic. The mixing effect of these components can change hour by hour and the retrieved size distributions, during the same day, can correspond to both alpha values $\leq 0.5$ and $>0.5$. This explains why on July 17 , for example, size distributions belong to both groups. To sum up, daily averaged distributions can be approximated by unimodal functions except the one retrieved on July 19 when an inflection point can be identified around $0.48 \mu \mathrm{m}$ : in this case $\langle\alpha\rangle=0.56 \pm 0.04$.

The distribution retrieved during Tito, 2008, on June 25 can be considered as bimodal with fine mode maximum at $0.21 \mu \mathrm{m}$ and a less pronounced coarse mode with maximum at $1.08 \mu \mathrm{m}$. As verified by Calvello et al. [28], this is a typical case of particles mixing of different origin: in fact, anthropogenic particles coming from the Po valley have been loaded by the lowest paths $(500 \mathrm{~m}-1500 \mathrm{~m}$ a.g.l.), while the highest ones (3500 m-4500 m a.g.l.) have been moving for about three days very close to North African soil (Algeria, Morocco). Moreover, NAAPS maps highlight both dust and smoke clouds over the campaign site.

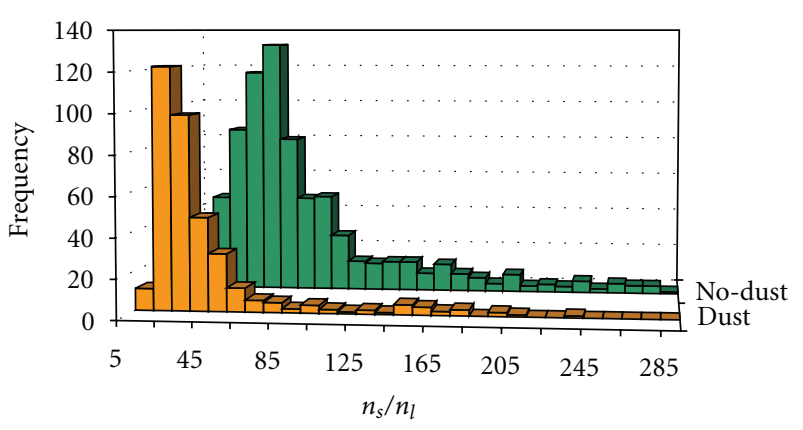

Figure 6: Histograms of $n_{s} / n_{l}$ for dust and no-dust data.

Finally, some consideration should be given to the parameter $n_{s} / n_{l}$ which represents the ratio small/large particles and was also used in the past by Lyamani et al. [8] as an indicator of mineral aerosol presence. In this study small particles fall in the size range $0.1 \mu \mathrm{m} \leq r \leq 0.27 \mu \mathrm{m}\left(n_{s}\right)$ while large ones in $0.27 \mu \mathrm{m}<r \leq 3 \mu \mathrm{m}\left(n_{l}\right)$. In Figure 6 the $n_{s} / n_{l}$ histograms, for all transported dust and no-dust data, are shown. Even in this case, in spite of different measurement sites and different aerosol size distributions, $89 \%$ of all dust data are distributed between 5 and 65 with a maximum at $n_{s} / n_{l}=15$, whilst no-dust data exhibit a maximum at $n_{s} / n_{l}$ $=55$ and the corresponding $89 \%$ of the measurements are widely distributed between 5 and 135 .

\section{Conclusions}

In this paper, a data set of radiometric measurements, including Saharan transported dust, has been analysed. These data come from eight measurement campaigns conducted in five sites (both urban and rural) located in the Western Mediterranean basin (South Italy and South Spain). In this study, similarities among measurements obtained across a very wide area have been looked for, thus changing the point of view of previous studies, which has been to analyse mineral aerosol parameters site by site. In particular, dustaffected data were identified when $\mathrm{AOD}_{780} \geq 0.15$ and alpha $\leq 0.4$. Moreover, five-day HYSPLIT-generated backtrajectories and NAAPS maps were used to support mineral particles detection. Then, grouping all these data, corresponding $\mathrm{AOD}_{780}$, Ångström parameters, and aerosol size distributions were analysed and their frequency distributions were shown. The main results are the following.

(1) $\mathrm{AOD}_{780}$ histogram for dust and mixed dust points covers the range $0.15-0.57$ with a maximum at 0.25 , while no-dust points extend from $0.03-0.39$ with a main peak at 0.11 and a secondary peak at 0.21 . This comparison highlights an overlapping region between the two distributions which is due to the advection of marine particles in no-dust histogram, as supported by HYSPLIT analysis.

(2) Alpha frequency distributions for both dust/mixed dust and no-dust points are broad and extend, respectively, from $0.20-1.40$ (mean value 0.70 , standard deviation 0.33 ) and from $0.60-4.55$ (mean value 
1.57, standard deviation 0.56). Even in this case an overlapping region has been found from 0.731.40 that, for low alpha values, can be explained by the presence of marine particles or soil particles uplifted by local wind in no-dust data, while higher alpha values in dust distribution correspond to the simultaneous presence of mineral and anthropogenic particles.

(3) The scatter-plot alpha parameter versus $\mathrm{AOD}_{780}$ shows all dust/mixed dust points to follow a decreasing function when $\mathrm{AOD}_{780}$ values increase and, again a superimposing area $(0.73 \leq \alpha \leq 1.40$ and $0.10 \leq$ $\mathrm{AOD}_{780} \leq 0.24$ ) with both dust and no-dust data.

(4) Dust-affected volume size distributions have been found to be differently shaped such as unimodal and bimodal with one case of three-modal function but, generally, the coarse mode of particles is prevailing over the fine one. They have been analysed according to their corresponding alpha values: $\alpha \leq 0.5$ for intense mineral particles advection and $\alpha>0.5$ for mineral particles mixed with smaller aerosols. In the first group bimodal distributions with the second mode in one case well depicted (Tito 2001, maximum at $0.94 \mu \mathrm{m}$ ) and poorly defined in other cases (Granada 2006) have been found. A case of trimodal shape (Tito 2008) has been found due to the simultaneous presence of anthropogenic, mineral, and sea-salt particles. In the second group, unimodal and bimodal distributions have been retrieved, showing small deviations from Junge-like shape, probably due to sea-salt and anthropogenic aerosol differently mixed with mineral uplifted aerosols.

(5) Finally, considering the ratio of small/large particles concentration $n_{s} / n_{l}$ and their frequency distribution, $89 \%$ of dust data are in the range $5-65$, with a maximum at 15 , while $89 \%$ of no-dust data are in the range $5-135$, with a maximum at 55 .

To conclude, mineral particles detected in the Western Mediterranean area show common properties, such as the shape of size distributions, or the small/large particles ratio, independently from the source regions, air-mass history, and measurement site characteristics. These common optical properties could be used to improve dust microphysical and optical parameterization in radiative transfer models.

\section{Acknowledgment}

This work has been partially funded by the project "Integrated Action Italy-Spain" carried out in cooperation with Professor Alados-Arboledas of Granada University (Spain), HI-2004-0219.

\section{References}

[1] P. Formenti, M. O. Andreae, T. W. Andreae et al., "Aerosol optical properties and large-scale transport of air masses: observations at a coastal and a semiarid site in the eastern
Mediterranean during summer 1998," Journal of Geophysical Research D, vol. 106, no. 9, pp. 9807-9826, 2001.

[2] G. Pace, A. di Sarra, D. Meloni, S. Piacentino, and P. Chamard, "Aerosol optical properties at Lampedusa (Central Mediterranean). 1. Influence of transport and identification of different aerosol types," Atmospheric Chemistry and Physics, vol. 6, no. 3, pp. 697-713, 2006.

[3] D. Meloni, A. di Sarra, G. Biavati et al., "Seasonal behavior of Saharan dust events at the Mediterranean island of Lampedusa in the period 1999-2005," Atmospheric Environment, vol. 41, no. 14, pp. 3041-3056, 2007.

[4] N. Kalivitis, E. Gerasopoulos, M. Vrekoussis et al., "Dust transport over the eastern mediterranean derived from total ozone mapping spectrometer, aerosol robotic network, and surface measurements," Journal of Geophysical Research D, vol. 112, no. 3, Article ID D03202, 2007.

[5] M. Santese, F. de Tomasi, and M. R. Perrone, "Advection patterns and aerosol optical and microphysical properties by AERONET over south-east Italy in the central Mediterranean," Atmospheric Chemistry and Physics, vol. 8, no. 7, pp. 18811896, 2008.

[6] L. Alados-Arboledas, H. Lyamani, and F. J. Olmo, "Aerosol size properties at Armilla, Granada (Spain)," Quarterly Journal of the Royal Meteorological Society, vol. 129, no. 590, pp. 13951413, 2003.

[7] F. Esposito, L. Leone, G. Pavese, R. Restieri, and C. Serio, "Seasonal variation of aerosols properties in South Italy: a study on aerosol optical depths, Angström turbidity parameters and aerosol size distributions," Atmospheric Environment, vol. 38, no. 11, pp. 1605-1614, 2004.

[8] H. Lyamani, F. J. Olmo, and L. Alados-Arboledas, "Saharan dust outbreak over southeastern Spain as detected by sun photometer," Atmospheric Environment, vol. 39, no. 38, pp. 7276-7284, 2005.

[9] J. Lelieveld, H. Berresheim, S. Borrmann et al., "Global air pollution crossroads over the Mediterranean," Science, vol. 298, no. 5594, pp. 794-799, 2002.

[10] L. Perez, A. Tobias, X. Querol et al., "Coarse particles from saharan dust and daily mortality," Epidemiology, vol. 19, no. 6, pp. 800-807, 2008.

[11] N. Kubilay, T. Cokacar, and T. Oguz, "Optical properties of mineral dust outbreaks over the north-eastern Mediterranean," Journal of Geophysical Research, vol. 108, no. 4666, 10 pages, 2003.

[12] G. P. Gobbi, Y. J. Kaufman, I. Koren, and T. F. Eck, "Classification of aerosol properties derived from AERONET direct sun data," Atmospheric Chemistry and Physics, vol. 7, no. 2, pp. 453-458, 2007.

[13] D. Kim, M. Chin, H. Yu et al., "Dust optical properties over North Africa and Arabian Peninsula derived from the AERONET data set," Atmospheric Chemistry and Physics Discussions, vol. 11, no. 7, pp. 20181-20201, 2011.

[14] A. Smirnov, B. N. Holben, I. Slutsker, E. J. Welton, and P. Formenti, "Optical properties of Saharan dust during ACE 2," Journal of Geophysical Research D, vol. 103, no. 21, pp. 2807928092, 1998.

[15] H. Lyamani, F. J. Olmo, A. Alcantara, and L. AladosArboledas, "Atmospheric aerosols during the 2003 heat wave in southeastern Spain I: spectral optical depth," Atmospheric Environment, vol. 40, no. 33, pp. 6453-6464, 2006.

[16] G. Pavese, F. de Tomasi, M. Calvello, F. Esposito, and M. R. Perrone, "Detection of Sahara dust intrusions during mixed advection patterns over south-east Italy: a case study," Atmospheric Research, vol. 92, no. 4, pp. 489-504, 2009. 
[17] P. Formenti, L. Schutz, Y. Balkanski et al., "Recent progress in understanding physical and chemical properties of African and Asian mineral dust," Atmospheric Chemistry and Physics, vol. 11, pp. 8231-8256, 2011.

[18] C. Toledano, M. Wiegner, M. Garhammer et al., "Spectral aerosol optical depth characterization of desert dust during SAMUM 2006," Tellus, vol. 61, no. 1, pp. 216-228, 2009.

[19] E. Ilyinskaya, V. I. Tsanev, R. S. Martin et al., "Near-source observations of aerosol size distributions in the eruptive plumes from Eyjafjallajökull volcano, March-April 2010," Atmospheric Environment, vol. 45, no. 18, pp. 3210-3216, 2011.

[20] F. Esposito, S. Mari, G. Pavese, and C. Serio, "Diurnal and nocturnal measurements of aerosol optical depth at a desert site in Namibia," Aerosol Science and Technology, vol. 37, no. 4, pp. 392-400, 2003.

[21] U. Amato, D. di Bello, F. Esposito, C. Serio, G. Pavese, and F. Romano, "Intercomparing the Twomey method with a multimodal lognormal approach to retrieve the aerosol size distribution," Journal of Geophysical Research D, vol. 101, no. 14, pp. 19267-19275, 1996.

[22] H. Gonzàlez and J. A. Ogren, "Sensitivity of retrieved aerosol properties to assumptions in the inversion of spectral optical depths," Journal of the Atmospheric Sciences, vol. 53, no. 24, pp. 3669-3683, 1996.

[23] P. Alpert, B. U. Neeman, Y. Shay-El et al., "Intermonthly variability of cyclone tracks in the mediterranean," Journal of Climate, vol. 3, no. 12, pp. 1474-1478, 1990.

[24] A. Fotiadi, N. Hatzianastassiou, E. Drakakis et al., "Aerosol physical and optical properties in the Eastern Mediterranean Basin, Crete, from Aerosol Robotic Network data," Atmospheric Chemistry and Physics, vol. 6, no. 12, pp. 5399-5413, 2006.

[25] A. di Sarra, T. di Iorio, M. Cacciani, G. Fiocco, and D. Fuà, "Saharan dust profiles measured by lidar at Lampedusa," Journal of Geophysical Research D, vol. 106, no. 10, pp. 1033510347, 2001.

[26] D. G. Kaskaoutis, H. D. Kambezidis, N. Hatzianastassiou, P. G. Kosmopoulos, and K. V. S. Badarinath, "Aerosol climatology: dependence of the Angstrom exponent on wavelength over four AERONET sites," Atmospheric Chemistry and Physics Discussions, vol. 7, no. 3, pp. 7347-7397, 2007.

[27] O. Dubovik, B. Holben, T. F. Eck et al., "Variability of absorption and optical properties of key aerosol types observed in worldwide locations," Journal of the Atmospheric Sciences, vol. 59, no. 3, pp. 590-608, 2002.

[28] M. Calvello, F. Esposito, F. Pavese, and C. Serio, "Physical and optical properties of atmospheric aerosol by in-situ and radiometric measurements," Atmospheric Chemistry and Physics, vol. 10, pp. 2195-2208, 2010. 

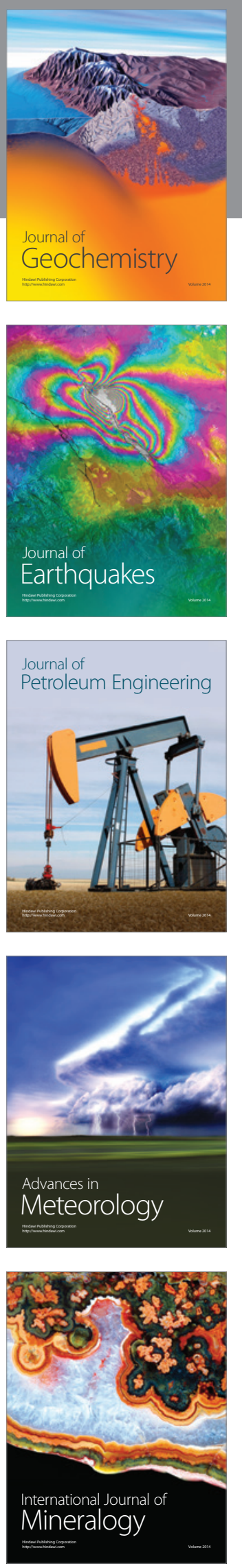
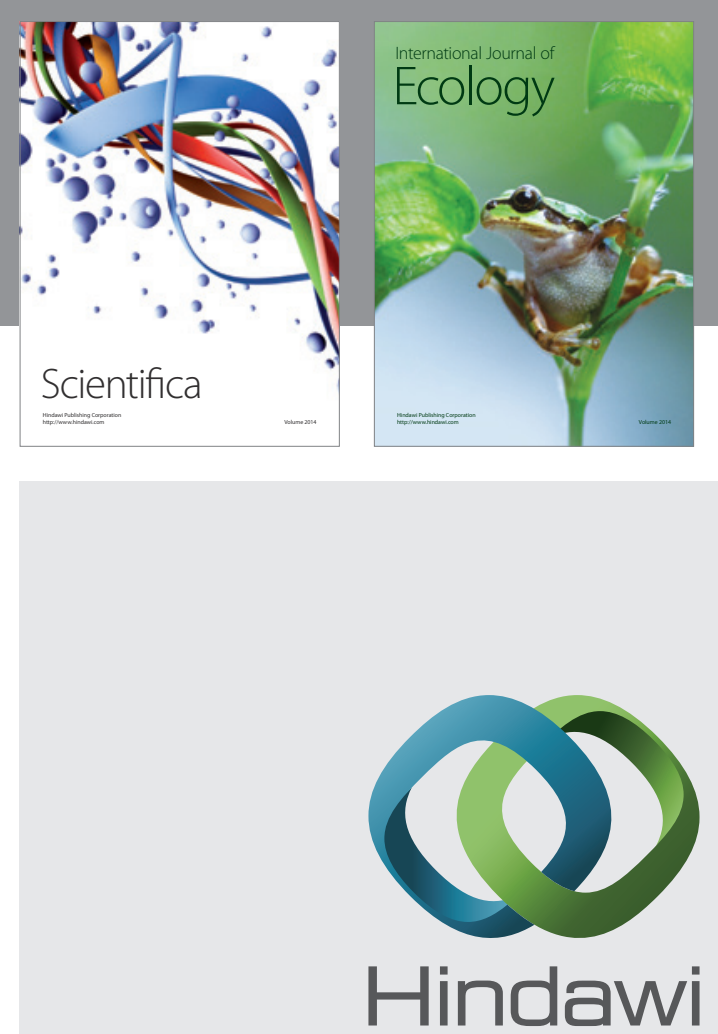

Submit your manuscripts at http://www.hindawi.com
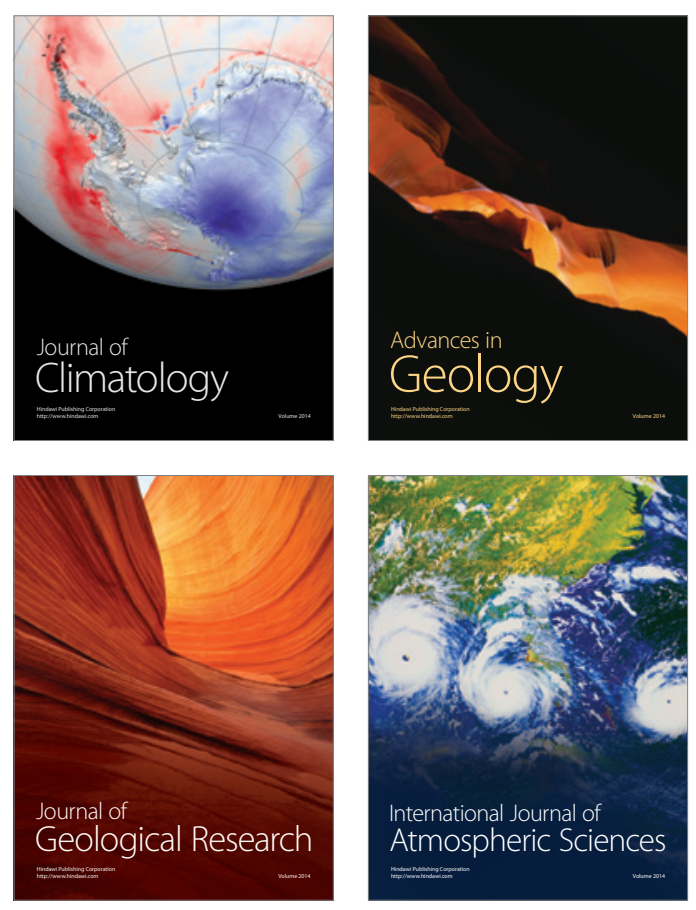
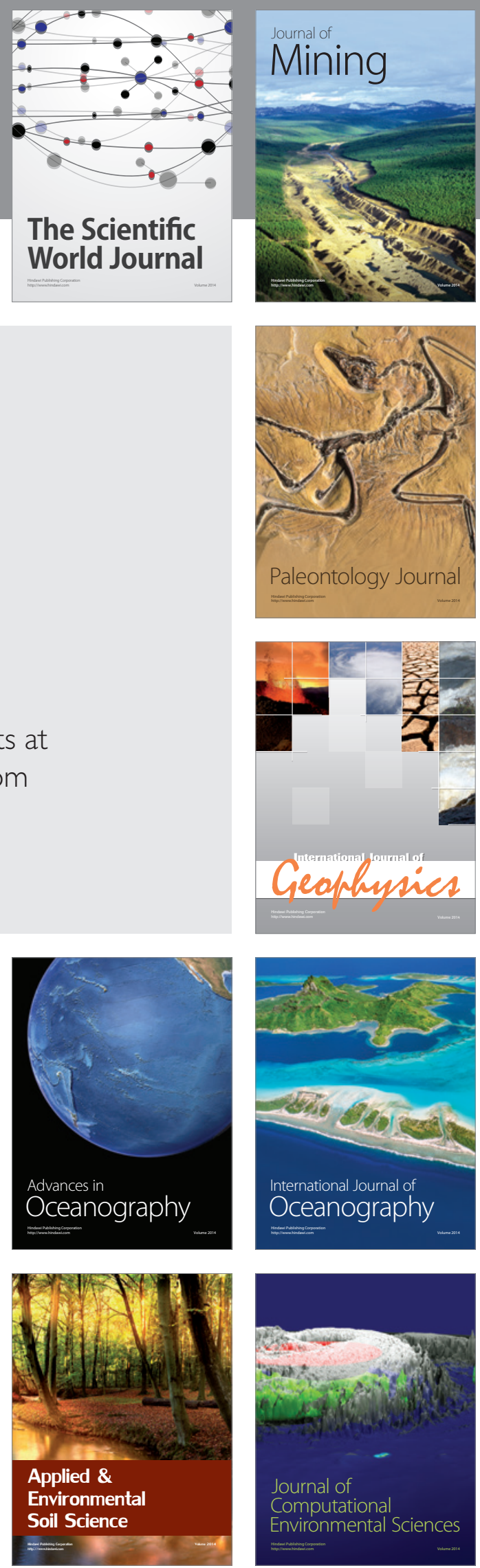